\title{
The Impact of Downside Risk on Expected Return: Evidence from Emerging Economies
}

\author{
Hassan Raza*, Arshad Hasan ${ }^{* *}$ and Abdul Rashid ${ }^{* * *}$
}

\begin{abstract}
This paper investigates the comparative relationship between the downside risk adjusted CAPM and traditional CAPM. The premise of the traditional CAPM is that the expected return is based on the incidence of systematic risk (beta), which has been assumed to be homogenous for both the developed, and the emerging stock markets. However, empirical results are not aligned with this assumption, as the basic risk and return relationship happens to be negative, and insignificant in the case of emerging markets. This may be due to the emerging stock markets' distinct characteristics (i.e. high volatility, low liquidity, and less availability of historical data). To deal with the said issue, extent literature supports the use of the semivariance methodology $(S V-M)$ for emerging markets, instead of the mean-variance $(M-V)$ method. Therefore, this study referred to the Fama and Macbeth (1973) methodology that was applied over monthly data ranging from June, 2000 to June, 2018. Results indicate that there is a positive relationship between the risks (downside and traditional beta) and the expected return. Moreover, results also reveal that downside risk has more significance and explanatory power as compared to the traditional beta. Hence, as per the above findings, the study suggests using the semi-variance methodology for the calculation of the expected returns in emerging economies. However, the significance of the residuals, and beta square terms in both methodologies clearly indicate that there is a need to adjust and incorporate more risk factors, as well as an element of non-linearity while arriving at a probable risk and return relationship.
\end{abstract}

Keywords: Mean Variance, Semi-Mean Variance, Downside Risk, Downside CAPM, Traditional CAPM and Fama-Macbeth Regression.

JEL Classification: G11, G12, G14, F20

\footnotetext{
${ }^{*}$ Lecturer, National University of Modern Languages, Islamabad, Pakistan.

${ }^{* *}$ Associate Professor, Capital University of Science and Technology, Islamabad, Pakistan.

${ }^{* * *}$ Associate Professor, International Institute of Islamic Economics (IIIE), International Islamic University, Islamabad, Pakistan.
} 


\section{Introduction:}

An investment decision is based on three determinants; the future cash flow, the projected life span and the discount rate. The effectiveness of an investment decision depends on how these three factors are accessed by the investor. The estimation of cash flow usually requires immense understanding of the project before it is implemented. The project life span is also an important factor to consider as a change in this will cause disruption in the whole perspective of the project. However, past literature clearly indicates that the discount rate is used as a compass while making critical investment decisions, and the corporate market theory provides several ways in which one can arrive on the appropriate discount rate. This discount rate may be termed as the cost of capital. Moreover, this cost of equity is considered to be an integral cost of capital. Capital asset pricing models are a renowned measure to calculate the cost of equity (Bekaert, Geert and Harvey, 1995; Pereiro, 2006). Different authors report that corporate manager mostly used the CAPM for the calculation of equity, instead of any other model (Ehrhardt \& Brigham, 2011; Bruner, Eades, Harris, \& Higgins, 1998; Graham \& Harvey, 2001; Jenkinson, 2006). However, the authors also reported a considerable variation in the use of CAPM for the said purpose (Bruner et al., 1998).

Previous studies in this discipline have also shed light on how the estimations of the discount rate through capital asset pricing theory may also vary from emerging markets to the more developed markets (Geert Bekaert \& Harvey, 1995; Estrada, 2000). Geert Bekaert and Harvey (2002), and Sabal (2004) reported that emerging economies are more volatile, less integrated and lower the trading volume. Moreover, not only are they smaller in size, but the traditional capital asset pricing will not be able to drive and lead the risk and return relationship (Solnik, 1973).

The pioneer study on the concept of emerging markets is perhaps by Harvey (1995), where he found that the systematic beta is low and largely insignificant. Subsequent studies have since then reported somewhat similar results, that eventually show that the beta and returns are actually unrelated (Adams \& Thornton, 2009; Geert Bekaert, Erb, Harvey, \& Viskanta, 1996; Estrada, 2002a; Estrada \& Serra, 2005).

Empirical studies have also reported that the returns' distributions in the emerging markets are more skewed, rather than symmetrical, as the 
CAPM expected. Kahneman and Tversky (1979) explain this skewed behavior in the Prospect Theory, and Gul (1991) explains this in his Disappointment Aversion Theory, where they cumulatively state that investors dislike the downside deviation more than the upside deviations. So, in order to capture this downside behavior, many studies have subsequently used the downside beta in the CAPM model, rather than the traditional beta. Even though definitive theoretical support is available for the downside beta, still, a limited amount of work has been seen on an empirical basis, especially in the aspect of the investors' preference for upside and downside risks (Rashid \& Hamid, 2015; Raza, 2018).

The previous work in this aspect can also be referred to for the adjustment of more than one risk factor that affects the expected returns. Fama and French (1992) find out that the adjustment of the size and value factor into the existing CAPM will improve the explanatory power of the model. Interestingly, the same results are reported by many other researchers across time and cross section. However, criticism can still be seen in the use of these factors. According to Perold (2004), the size and value factors are not about risk at all. That is to say that, if the size is a risk factor, then the small firms tend to combine themselves to form large firms. Likewise, the value effect is based on allotting equal weightage to small and large firms, which are already lying in the capitalization-weighted value indexes. Perold (2004) also concluded that till the actual risk attributes that underlies behind these factors have been identified, the explanatory power of the model will be in doubt. Hence, such models have a limited scope of application. So this particular work is limited to the traditional, and downside CAPM.

Keeping this in mind, it must be noted that the study revolves around two basic research questions. These include whether traditional beta explains the mean returns of emerging markets, or whether the downside and upside beta have more explanatory power in this relationship. This study also aims to contribute towards the existing knowledge on capital market theory. This task will be undertaken by proving a recent empirical analysis with strong methodology, along with a comparison between the improved framework (D-CAPM), and the existing framework of CAPM. The data used in this paper is quite in-depth, and also addresses the problem that comes with the assumption of normality. The results of this study provide significant help to investors, corporate managers, and project managers for a better selection of their discount rate in emerging markets. 


\section{Theoretical Background}

Studies on downside risk show that there is a major improvement in the literature of portfolio and asset pricing theory. This phenomenon itself has started getting the right kind of attention recently as it involves the calculation of discount rate in emerging markets for the purpose of making wise investments decisions, although the discussion of this topic started from Roy (1952). According to Roy (1952), investors, while making investments, first focus to save their principal amount, and accept any minimum returns that conserve its principle amount. This "safety first" approach is termed as the downside risk. In this regard, Markowitz (1959) recognized the importance of the downside risk. According to him, investors are more interested into downside risk, mainly due to the fact that they are more concerned about the safety of their principal amount, and secondly due to the returns not being normally distributed in most of markets. Markowitz (1959), however, prefers to deal in total risk, just because its computation is simple.

Quirk and Saposnik (1962), and Mao (1970), also believe that investors are more skewed towards the negative side of the returns instead of the positive side. Researchers like Simkowitz and Beedles (1978), Singleton and Wingender (1986), Chunhachinda, Dandapani, Hamid and Prakash (1997), and Rehmann et al. (2003), criticize the very basic assumption of the traditional CAPM, that propose that the returns follow the normal distributions, while in actuality, the distribution is highly skewed towards the emerging markets.

Jahankhani (1976) is probably the first one to empirically investigate the difference between the mean-variance, and semi-variance technique in order to successfully calculate the systematic risk. Results of this study indicate that the semi-variance beta provides a better explanation of the risk - return relationship, instead of the mean variance beta. However, some authors argue that these results may be due to the small sample biasness, as the authors took the sample from 1951 to 1969.

Furthermore, some authors have also worked on the semi-variance methodology for the calculation of downside, as well as the upside beta. Kraus and Litzenberger's (1976) have extensively worked on the downside and upside beta in higher order movements. Their results supported the semi-variance technique as it tends to produce better results than the methods used before. Similarly, Fabozzi and Francis (1977) came up with an innovative idea as he adjusted the downside and upside beta as a 
random coefficient. The results however indicate that there is no significant relationship between risk and return under the semi-variance methodology. Subsequently, the work of Kim and Zumwalt (1979) reports significant results, with a downside beta and expected return, but the upside beta reports a negative coefficient. The work of Chen (1982) discussed that this issue usually arises due to the multicollinearity and proposed that the time varying regression model should be used instead of the two pass regression.

Estrada (2002a) reflects that the downside CAPM tends to perform better in emerging markets, as compared to the same in traditional CAPM. The downside CAPM explains 55\% of the variations in the mean returns in the emerging markets. The results display a weak correlation between the emerging markets and the world market portfolio, which indicates a partial integration nature of an emerging market. Results also reveal that there is an insignificant relationship between beta, and the returns, while on the other side the downside beta is statistically significant with the mean returns. The author argues that this might be due to the reason that the world market portfolio has been inefficient in explaining the stocks returns of the emerging markets. Harvey's (2000) work on the downside beta, and the subsequent results suggest that this method produces better results for emerging economies, than that for developed economies.

In addition to this, Estrada's (2002b) study on the downside CAPM, for both developed and emerging economies, calculates the CAPM beta, and the downside beta, on each return, with respect to the MSCI World Index. The traditional CAPM, as well as the downside CAPM, report significant results. However, but later these results show an explanatory power of almost $47 \%$. The author has divided the sample into developed and emerging markets. He has then investigated the relative efficiency of both the models. The interesting facts that arise after seeing the results are that all the risk factors in the emerging markets' data are significant with respect to the developed markets, where none of the risk factors are significant, and the downside CAPM still outperforms the traditional CAPM.

Different studies emphasize that the economic significance of the risk returns paradigm is more important for practitioners, than it being statistically significant (Estrada \& Serra, 2005). Under the same influence, many authors have estimated the risk and return relationship, using the Fama and Macbeth (1973) methodology, which falls under the GMM framework, in order to identify the variables for the calculation of cost to equity. Along with this, they have also carried out economic analysis, for 
the purpose of identifying the variables that produce the most profitable portfolios. Their results report a weak statistical relationship between the downside risk and return, but the downside risk happens to have the largest impact on returns, while staying within the economic framework.

Many different methods are available in the literature to cater to the adjustment of the downside risk into the CAPM beta. Hogan and Warren (1974) used the semi-variance, and the covariance methodology, instead of the variance co-variance, in order to arrive at the downside adjusted CAPM. Similarly, Bawa and Lindenberg (1977), and Harlow (1991) also developed a downside adjusted beta. However, they did this using the Mean Lower Partial Moments methodology, instead of the Semi-Variance methodology. The difference between these varying methodologies is only the estimation of the target rate of return (Rashid \& Hamid, 2015). Estrada (2002) further extended the Semi-Variance methodology by dividing the downside volatility of both the stock and the market. The difference in Estrada's (2002) methodology, as compared to the other two methodologies is that their methodologies assume that the co-semi variance of all assets is homogenous. Moreover, they also infer that the deviations calculated from the both methods will be lower than their mean level, which may result in weak estimations of the risk and return relationship. Hence, the use of Estrada's (2002) work is more suitable in this regard (Rashid \& Hamid, 2015).

The contextual review of the literature reveals that there are a few studies based on the comparative analysis of the mean-variance and the semi-variance methodologies over BRICS (Brazil, Russia, India, China and South Africa) plus Pakistan. Rashid and Hamid (2015) worked on the semivariance methodology, by using the abovementioned techniques, and found a better explanation of the expected returns in the banking sector. Sehgal and Pandey (2018) worked on the Indian stock market by using a different measure of the downside risk, and the particular study concluded that there tends to be a significant relationship between these downside measures. Galagedera (2009); Galagedera (2007) and, Iqbal, Brooks and Galagedera (2010) have worked on these emerging markets, and have reported that the downside risk has a better explanatory power than other risk measures in asset pricing. 
This study aims to analyze the comparative estimations of the risk and return relationship, by using both the mean variance and the semivariance techniques. This research also provides a significant contribution towards the existing literature, by estimating and evaluating the meanvariance capital asset pricing model, as well as the downside risk adjusted capital asset pricing model. Moreover, the aim is to test the significance of these models for emerging markets, in terms of the recent data explored in this context.

\section{Data and Methodology}

This study has used and referred to six major stock markets of the world, i.e. Brazil, Russia, India, China, South Africa and Pakistan. The purpose was to test the mean variance and semi-variance methodologies, and to test and validate the traditional as well as the downside CAPM. All the companies which have a price related history from June, 2000 to June, 2018, are included into the study sample. To justify this research aim, the study used the Fama and Macbeth (1973) methodology on the individual stocks of each market. This methodology proposes an approach which is based on two steps, i.e., in the first step, the time variant beta is measured by using the time series regression for the individual stock over the market premium. In the second step, the excess security return is regressed on the estimated beta, which was derived from the first steps. At the end, the slopes and the betas obtained are averaged out and tested for their significance.

Multiple hypotheses have been developed to test the risk and return relationship. The time variant beta that has been obtained from the first pass regression of Fama and Macbeth (1973) model are used to arrive at the risk and return relationship.

$$
\begin{gathered}
R_{i}-R_{f}=\lambda_{o}+\lambda_{1} \beta_{i}+\mu_{i}---1 \text { (For CAPM) } \\
\left.R_{i}=\lambda_{o}+\lambda_{1} \beta_{i}^{D}+\mu_{i} \text {--------------(For D-CAPM }\right)
\end{gathered}
$$

The linear assumption of the capital asset pricing model is tested by adding the squared terms of the systematic risk. This is added as an explanatory variable into the risk and return framework.

$$
R_{i}-R_{f}=\lambda_{o}+\lambda_{1} \beta_{i}+\lambda_{2} \beta_{i}^{2}+\mu_{i} \text {-------------(For CAPM) }
$$




$$
R_{i}=\lambda_{o}+\lambda_{1} \beta_{i}^{D}+\lambda_{2} \beta_{i}^{2 D}+\mu_{i}^{-------------(F o r ~ D-C A P M) ~}
$$

To check that the systematic risk is the only a measure of expected return, the residual of error term is added to the model.

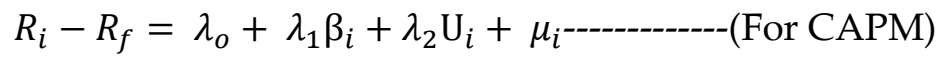

$$
\begin{aligned}
& R_{i}=\lambda_{o}+\lambda_{1} \beta_{i}^{D}+\lambda_{2} \cup_{i}^{D}+\mu_{i}-\cdots----(F o r \text { D-CAPM })
\end{aligned}
$$

The joint hypothesis is tested out by including all these variables, in order for the explanatory variable to arrive at the risk and return relationship.

$$
\begin{aligned}
& \left.R_{i}-R_{f}=\lambda_{o}+\lambda_{1} \beta_{i}+\lambda_{2} \beta_{i}{ }^{2}+\lambda_{3} U_{i}+\mu_{i}--1 \text {-or CAPM }\right) \\
& R_{i}=\lambda_{o}+\lambda_{1} \beta_{i}^{D}+\lambda_{2} \beta_{i}^{2 D}+\lambda_{2} \cup_{i}^{D}+\mu_{i}----(F o r \text { D-CAPM })
\end{aligned}
$$

The fifth hypothesis is performed only for the downside CAPM, where both the upside and downside beta are regressed against the mean returns of firms, into a single model, as recommended by (Estrada, 2007).

$$
R_{i}=\lambda_{o}+\lambda_{1} \beta_{i}^{D}+\lambda_{2} \beta_{i}^{2 D}+\lambda_{3} \cup_{i}^{D}+\lambda_{1} \beta_{i}^{U}+\mu_{i}
$$

\section{Empirical Results for the Mean-Variance CAPM}

The Following results are reported by taking the averages of slopes and standard errors, in order to test the null hypothesis and adjusted Rsquares, which are derived from Fama and Macbeth's (1973) second step regression. These results are obtained by a monthly cross sectional regression, which eventually averages out for all the lopes, standard errors and associated figures as reported in table 1. 


\section{Table 1: Results for Traditional CAPM}

\begin{tabular}{|c|c|c|c|c|c|c|}
\hline Country & Model & $\boldsymbol{\beta}_{\boldsymbol{i}}$ & $\beta_{i}{ }^{2}$ & $\mathbf{U}_{\boldsymbol{i}}$ & Constant & $\begin{array}{l}\text { Adj. R- } \\
\text { squared }\end{array}$ \\
\hline \multirow{4}{*}{ 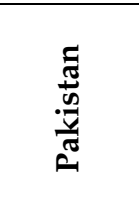 } & 1 & $0.0162^{* *}$ & & & $-0.0983^{* * *}$ & 0.039 \\
\hline & 2 & $0.0700^{* * *}$ & $-0.0616^{* * *}$ & & $-0.0880^{* * *}$ & 0.337 \\
\hline & 3 & $0.0193^{* * *}$ & & $\begin{array}{c}- \\
7.862^{* * * *}\end{array}$ & $-0.0665^{* * *}$ & 0.21 \\
\hline & 4 & $0.0932^{* * *}$ & $-0.0906^{* * *}$ & $5.557^{*}$ & $-0.106^{* * *}$ & 0.357 \\
\hline \multirow{4}{*}{ 氕 } & 1 & -0.00705 & & & $-0.00485^{* * *}$ & 0.014 \\
\hline & 2 & -0.00598 & -0.0147 & & $-0.00444^{* * *}$ & 0.019 \\
\hline & 3 & -0.00711 & & -1.244 & $-0.00327^{*}$ & 0.021 \\
\hline & 4 & -0.0162 & 0.119 & -9.943 & 0.0045 & 0.026 \\
\hline \multirow{4}{*}{$\stackrel{\Xi}{\Xi}$} & 1 & 0.00212 & & & $0.00260^{* * *}$ & 0.004 \\
\hline & 2 & 0.00158 & $0.0163^{*}$ & & $0.00242^{* * *}$ & 0.009 \\
\hline & 3 & 0.0021 & & $4.366^{*}$ & $0.00158^{* * *}$ & 0.011 \\
\hline & 4 & 0.00288 & -0.0243 & 10.07 & 0.00052 & 0.011 \\
\hline \multirow{4}{*}{$\stackrel{\pi}{\overparen{\pi}}$} & 1 & $0.00302^{* *}$ & & & $0.000988^{* * *}$ & 0.006 \\
\hline & 2 & $0.00302^{* *}$ & 0.0000285 & & $0.000986^{* * *}$ & 0.006 \\
\hline & 3 & $0.00302^{* *}$ & & -0.435 & 0.00117 & 0.006 \\
\hline & 4 & 0.00241 & 0.0111 & -7.346 & 0.00346 & 0.007 \\
\hline \multirow{4}{*}{ 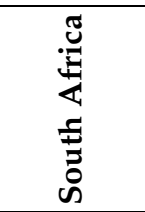 } & 1 & $0.00386^{* *}$ & & & -0.000631 & 0.022 \\
\hline & 2 & 0.00153 & $-0.00519^{* * *}$ & & -0.00112 & 0.055 \\
\hline & 3 & $0.00416^{* *}$ & & $\begin{array}{c}- \\
5.938^{* * *}\end{array}$ & $0.00547^{* *}$ & 0.063 \\
\hline & 4 & 0.00912 & 0.00456 & -10.39 & 0.0105 & 0.065 \\
\hline \multirow{4}{*}{ 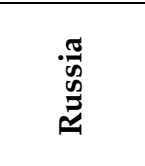 } & 1 & -0.00181 & & & $-0.00497^{* * *}$ & 0.009 \\
\hline & 2 & 0.000458 & -0.00219 & & $-0.00493^{* * *}$ & 0.015 \\
\hline & 3 & -0.0018 & & -3.563 & -0.000749 & 0.021 \\
\hline & 4 & -0.0162 & 0.014 & $-20.02^{*}$ & 0.0185 & 0.035 \\
\hline
\end{tabular}

${ }^{*} \mathrm{p}<0.1,{ }^{* * *} \mathrm{p}<0.01,{ }^{* *} \mathrm{p}<0.05$

In the first phase of the analysis, the systematic risk (Beta) has been computed through the 36 months' recursive rolling window. In the second phase of the analysis, the cross-sectional regression has been estimated and disclosed, in Table 1.

Table 1 exhibits the insignificant results for Brazilian, Russian and the Chinese markets for all the reported hypothesis. The results indicate that the capital asset pricing model is unable to explain the variations in the mean returns of the firms in these countries through the systematic beta. The results for hypothesis 1 indicate that the risk and return relationship is significant only for Pakistan, India and South Africa, where the systematic beta significantly explains the variations of mean returns, but with low predictive power of the R-square which lies at only $3 \%$. Model 
2 exhibits the results after incorporating the non-linearity assumption, whereby the Pakistani and South African markets report a significant presence of non-linearity.

The third hypothesis tests the adequacy of the beta factor. The results in this regard exhibit that the residuals of Pakistan and South African markets are statistically significant, while the same is insignificant in the Indian market. The significant value of the residual terms indicate the inadequacy of the beta factor, while the insignificant value indicates the applicability of the CAPM. These results show that in Pakistan and South Africa, there is still a need to include the other factors in the market premium, but in the Indian market, the beta factor properly explains the risk and return relationship.

The joint hypothesis is tested by taking the beta factor, its square term, and the residual term on the mean returns of firms into a single model. The consequences of this hypothesis indicate that the beta factor is only significant in the Pakistani market, where all the other markets report insignificant results. The intercept term differs considerably from zero, which indicates the presence of risk free assets into each model. However, a negative value is opposite to the main assumption of Sharpe (1964). This suggests that the traditional CAPM model does not hold true for these countries over the examined period (2000 to 2018), except that in Pakistan. These results are mostly related to Iqbal, Brooks and Galagedera (2010), and Rashid and Hamid (2015) studies which discuss the case of Pakistan, and Korkmaz, Cevik and Gurkan (2010) in the case of Brazil, China, India, Russia and South Africa.

\section{Empirical Results For The Down-Side CAPM}

In the second step of the analysis, the semi-variance methodology of Estrada (2002) is used to calculate the downside beta. Furthermore, this beta is regressed a cross sectional basis in order to arrive at the slopes, standard errors and adjusted r-square, which are eventually averaged out, and results are reported in Table 2. 
Table 2: Results for the Downside CAPM

\begin{tabular}{|c|c|c|c|c|c|c|c|}
\hline Country & Model & $\beta_{i}^{D}$ & $\beta_{i}^{2 D}$ & $\mathrm{U}_{i}^{D}$ & $\beta_{i}^{U}$ & Constant & $\begin{array}{l}\text { Adj. R- } \\
\text { squared }\end{array}$ \\
\hline \multirow{5}{*}{$\frac{y}{\pi}$} & 1 & $0.0153^{* * *}$ & & & & $0.0115^{* * *}$ & $0 . .225$ \\
\hline & 2 & $0.0359^{* * *}$ & $-0.0091^{*}$ & & & $0.0111^{* * *}$ & 0.436 \\
\hline & 3 & $0.0692^{* * *}$ & & $-0.0546^{* *}$ & & $0.0165^{* * *}$ & 0.554 \\
\hline & 4 & $0.0367^{* * *}$ & -0.0062 & $-0.0460^{*}$ & & $0.0155^{* * *}$ & 0.556 \\
\hline & 5 & 0.0021 & & & $0.00734^{* *}$ & $0.0103^{* * *}$ & 0.1240 \\
\hline \multirow{5}{*}{$\begin{array}{l}\overline{\widetilde{N}} \\
\text { ص్ర }\end{array}$} & 1 & $00824^{* *}$ & & & & $0.00564^{* * *}$ & 0.1349 \\
\hline & 2 & $0.0053^{*}$ & $-0.026^{* * *}$ & & & $0.00642^{* * *}$ & 0.1880 \\
\hline & 3 & -0.0035 & & $-0.116^{* * *}$ & & $0.0155^{* * *}$ & 0.2540 \\
\hline & 4 & -0.0015 & -0.0073 & $-0.108^{* * *}$ & & $0.0150^{* * *}$ & 0.2590 \\
\hline & 5 & -0.0028 & & & 0.0052 & $0.00562^{* * *}$ & 0.1794 \\
\hline \multirow{5}{*}{ 苟 } & 1 & $0.00357^{*}$ & & & & $0.00332^{* * *}$ & 0.0070 \\
\hline & 2 & 0.0012 & 0.0178 & & & $0.00325^{* * *}$ & 0.0100 \\
\hline & 3 & $0.00328^{*}$ & & $-0.0646^{* * *}$ & & $0.00894^{* * *}$ & 0.0390 \\
\hline & 4 & 0.0000 & 0.0248 & $-0.0676^{* * *}$ & & $0.00911^{* * *}$ & 0.0450 \\
\hline & 5 & $0.00352^{*}$ & & & -0.0006 & $0.00342^{* * *}$ & 0.0070 \\
\hline \multirow{5}{*}{ } & 1 & \multicolumn{2}{|c|}{$.002104^{* * *}$} & & & $0.00518^{* * *}$ & 0.0155 \\
\hline & 2 & $.014146^{* * *}$ & $0.010^{* * *}$ & & & $0.00546^{* * *}$ & 0.0391 \\
\hline & 3 & \multicolumn{2}{|c|}{$.0066028^{* * *}$} & $-0.0304^{* * *}$ & & $0.00903^{* * *}$ & 0.0775 \\
\hline & 4 & $.0123167^{* * *}$ & -0.0012 & $-0.0296^{* * *}$ & & $0.00896^{* * *}$ & 0.0851 \\
\hline & 5 & \multicolumn{2}{|c|}{$0.00580^{* * *}$} & & -0.0007 & $0.00521^{* * *}$ & 0.0240 \\
\hline \multirow{5}{*}{ 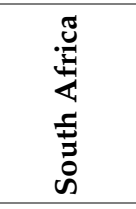 } & 1 & -0.0013 & & & & $0.00607^{* * *}$ & 0.0030 \\
\hline & 2 & $0.0129^{* * *}$ & $-0.011^{* * *}$ & & & $0.00352^{* * *}$ & 0.1150 \\
\hline & 3 & -0.0004 & & $-0.0937^{* * *}$ & & $0.0128^{* * *}$ & 0.2550 \\
\hline & 4 & 0.0023 & -0.0022 & $-0.0865^{* * *}$ & & $0.0118^{* * *}$ & 0.2580 \\
\hline & 5 & 0.0000 & & & $-0.00355^{*}$ & $0.00693^{* * *}$ & 0.0180 \\
\hline \multirow{5}{*}{ 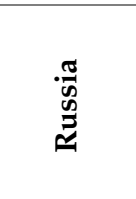 } & 1 & $-0.00248^{*}$ & & & & -0.0009 & 0.0210 \\
\hline & 2 & 0.0028 & -0.0035 & & & -0.0017 & 0.0340 \\
\hline & 3 & \multicolumn{2}{|c|}{$0.00287^{* *}$} & $-0.0530^{* * *}$ & & $0.00416^{* *}$ & 0.0910 \\
\hline & 4 & -0.0011 & -0.0012 & $-0.0508^{* * *}$ & & 0.0037 & 0.0930 \\
\hline & 5 & 0.0012 & & & $-0.005^{* * *}$ & -0.0006 & 0.0680 \\
\hline
\end{tabular}

In Table 2, results for downside CAPM are reported. The downside beta significantly explains the mean returns in hypothesis 1, for Pakistan, Brazil and India at the 95\% confidence interval. While in China and Russia this confidence interval is at $90 \%$. The results for South Africa is insignificant. The sign of the downside beta is positive, except for Russia, where the sign is against the theory. The downside risk model is more valid in these markets as compared to the traditional CAPM model. Although the issue of non-linearity and significance of residual term is still present in this model as well. Almost all the intercept values are statistically significant and positive as the CAPM expected. The power of the model varies from country to country, but it is still better than the traditional model. In Pakistan and Brazil, the downside CAPM shows more predictive power than in other countries. The results reported above indicate that the 
downside beta is statistically significant for all the models that clearly indicate the validity of the downside CAPM. However, the issue of nonlinearity and significant residuals also exists. It indicates that more variables may be incorporated into the downside capital asset pricing model so that the alpha becomes statistically insignificant.

\section{Conclusions}

The determination of the discount rate is an important decision in the pricing of any assets, in any stock market. Different methods have been developed for this purpose, but the capital asset pricing model is used mostly for this purpose. The multi-version CAPM model has been observed in the literature on the basis of different dynamics of the stocks markets in the world. This study tries to attempt an investigation into the emerging markets for the estimation of an appropriate discount rate. For this purpose, this study applies two different models i.e. the traditional CAPM and the downside CAPM, and compares their predictive power.

Due to different fundamentals of emerging markets i.e. high volatility, low size, low trading volume, then that in developed markets, multiple authors suggest the use of the semi-variance technique for the purpose of estimating the risk and return relationship (Estrada, 2007; Estrada \& Serra, 2005).

This study provides the comparative analysis between the traditional CAPM, and the downside CAPM. It does this by incorporating the most suitable methodology, and updated data for BRICS countries, and Pakistan, for the period of 2000 till 2018. The study also uses the monthly stock returns for all the listed companies which have a history for these selected years. Fama and Macbeth (1973) two-pass regression model has been employed for testing both the CAPM models, by taking the time invariant beta over a 36-month rolling window.

Results clearly indicate the superiority of the downside capital asset pricing model over the traditional capital asset pricing model, but still, problems of non-linearity and significant alpha exist. This means that a larger risk factor could be accommodated, along with the market risk premium, so that the basic assumptions of asset pricing theory can be retained.

In conclusion, the use of the downside capital asset pricing for the calculation of cost of equity in emerging countries is a recommended practice. This model has better predicative power than the traditional models, especially in emerging economies. 


\section{References}

Adams, M., \& Thornton, B. (2009). A comparison of Alternative approaches to equity valuation of privately held entrepreneurial firms. Journal of Finance and Accountancy, 1(2), 2-14.

B.H. Solnik. (1973). American Finance Association The International Pricing of Risk: An Empirical Investigation of the World Capital Market Structure. Journal of Finance, 29(2), 365-378.

Bawa, V. S., \& Lindenberg, E. B. (1977). Capital market equilibrium in a mean-lower partial moment framework. Journal of Financial Economics, 5(2), 189-200.

Bekaert, G, Erb, C. B., Harvey, C. R., \& Viskanta, T. E. (1996). The behavior of emerging market return. The Future of Emerging Capital Flows, 2(1), 107-173.

Bekaert, Geert, \& Harvey, C. R. (1995). The Cost of Capital in Emerging Markets. Duke University and Stanford University.

Bekaert, Geert, \& Harvey, C. R. (2002). Research in emerging markets finance: looking to the future. Emerging Markets Review, 3(4), 429-448.

Ehrhardt, M. C., \& Brigham, E. F. (2011). Financial management: theory and practice. South-Western Cengage Learning.

Bruner, R. F., Eades, K. M., Harris, R. S., \& Higgins, R. C. (1998). Best practices in estimating the cost of capital: survey and synthesis. Financial Practice and Education, 8, 13-28.

Chen, S. (1982). An Examination of Risk-Return Relationship in Bull and Bear Markets Using Time-Varying Betas. Journal of Financial And Quantitative Analysis, 17(2), 265-287.

Chunhachinda, P., Dandapani, K., Hamid, S., \& Prakash, A. J. (1997). Portfolio selection and skewness: Evidence from intemational stock markets. Journal of Banking \& Finance, 21, 143-167.

Estrada, J. (2000). The cost of equity in emerging markets: A downside risk approach. Emerging Markets Quarterly, 4(Fall 2000), 19-30. 
Estrada, J. (2002a). Mean-semivariance behavior (II): the D-CAPM. In EFMA 2002 London Meetings.

Estrada, J. (2002b). Systematic risk in emerging markets: The D-CAPM. Emerging Markets Review, 3(4), 365-379.

Estrada, J. (2007). Mean-semivariance behavior: Downside risk and capital asset pricing. International Review of Economics \& Finance, 16(2), 169185.

Estrada, J., \& Serra, A. P. (2005). Risk and return in emerging markets: Family matters. Journal of Multinational Financial Management, 15(3), 257-272.

Fabozzi, F. J., \& Francis, J. C. (1977). American Finance Association stability tests for alphas and betas over bull and bear market conditions. The Journal of Finance, 32(4), 1093-1099.

Fama, E. F., \& French, K. R. (1992). The cross-section of expected stock returns. The Journal of Finance, 47(2), 427-465.

Fama, E. F., \& MacBeth, J. D. (1973). Risk, return, and equilibrium: Empirical tests. Journal of political economy, 81(3), 607-636.

Galagedera, D. U A. (2009). Economic significance of downside risk in developed and emerging markets. Applied Economics Letters, 16(16), 1627-1632.

Galagedera, Don U.A. (2007). An alternative perspective on the relationship between downside beta and CAPM beta. Emerging Markets Review, 8(1), 4-19.

Graham, J. R., \& Harvey, C. R. (2001). The theory and practice of corporate finance: Evidence from the field. Journal of Financial Economics, 60(23), 187-243.

Gul, F. (1991). A theory of disappointment aversion. Econometrica, 59(3), 667-687.

Harlow, W. V. (1991). Asset Allocation in a Downside-Risk Framework. Financial Analysts Journal, 47(5), 28-40. 
Hogan, W. W., \& Warren, J. M. (1974). Toward the development of an equilibrium capital-market model based on semivariance. The Journal of Financial and Quantitative Analysis, 9(1), 1-11.

Iqbal, J., Brooks, R., \& Galagedera, D. U. A. (2010). Testing conditional asset pricing models: An emerging market perspective. Journal of International Money and Finance, 29(5), 897-918.

Jahankhani, A. (1976). E-V and E-S Capital Asset Pricing Models: Some Empirical Tests. 11(4), 513-528.

Jenkinson, T. (2006). Regulation and the cost of capital. International Handbook on Economic Regulation, 49(41), 4138-4147.

Kahneman, D., \& Tversky, A. (1979). Kahneman \& Tversky (1979) Prospect Theory - An analysis of decision under risk. Econometrica, 47(2), 263-292.

Kim, M. K., \& Zumwalt, J. K. (1979). An analysis of risk in bull and bear markets. Journal of Financial and Quantitative Analysis, 14(5), 10151025.

Korkmaz, T., Cevik, E. I., \& Gurkan, S. (2010). Testing of the international capital asset pricing model with Markov switching model in emerging markets. Investment Management and Financial Innovations, $7(1), 37-49$.

Kraus, A., \& Litzenberger, R. H. (1976). SKEWNESS PREFERENCE AND THE VALUATION OF RISK ASSETS. The Journal of Finance, 31(4), 1085-1100.

Mao, J. C. T. (1970). ESSENTIALS OF PORTFOLIO DIVERSIFICATION STRATEGY. The Journal of Finance, 25(5), 1109-1121.

Markowitz, H. (1959). Portfolio Selection: Efficient Diversification of Investments. Yale University Press.

Pereiro, L. E. (2006). The practice of investment valuation in emerging markets: Evidence from Argentina. Journal of Multinational Financial Management, 16(2), 160-183.

Perold, A. F. (2004). The capital asset pricing model. Journal of Economic Perspectives, 18(3), 3-24. 
Quirk, J. P., \& Saposnik, R. (1962). Admissibility and measurable utility functions. The Review of Economic Studies, 29(2), 140.

Rashid, A., \& Hamid, F. (2015). Downside risk analysis of returns on the Karachi Stock Exchange. Managerial Finance, 41(9), 940-957.

Raza, H. (2018). Is D-CAPM superior to CAPM? The case of Pakistan Stock Exchange. NUML International Journal of Business $\mathcal{E}$ Management, 13(1), 96-106.

Rehmann, H., Prakash, B., Wolf, E., Rueppel, A., De Rooij, J., Bos, J. L., \& Wittinghofer, A. (2003). Structure and regulation of the CAMPbinding domains of Epac2. Nature Structural Biology, 10(1), 26-32.

Roy, A. D. (1952). Safety First and the holding of assets. Econometrica: Journal of the Econometric Society, 20(3), 431-449.

Sabal, J. (2004). The discount rate in emerging markets: A guide. Journal of Applied Corporate Finance, 16(2-3), 155-166.

Sehgal, S., \& Pandey, A. (2018). Predicting financial crisis by examining risk-return relationship. Scientific Research Publishing, 8, 48-71.

Sharpe, W. F. (1964). Capital asset prices: A theory of market equilibrium under conditions of risk. The Journal of Finance, 19(3), 425-442.

Simkowitz, M. A., \& Beedles, W. L. (1978). Diversification in a ThreeMoment World. The Journal of Financial and Quantitative Analysis, 13(5), 927-941.

Singleton, J. C., \& Wingender, J. (1986). Skewness Persistence in Common Stock Returns. The Journal of Financial and Quantitative Analysis, 21(3), 335-341. 